\title{
Operative Management of Lumbar Degenerative Disc Disease
}

\author{
Yu Chao Lee ${ }^{1}$, Mario Giuseppe Tedesco Zotti ${ }^{1}$, Orso Lorenzo Osti ${ }^{2}$ \\ ${ }^{1}$ Spinal Surgery Unit, Department of Orthopaedics and Trauma, Royal Adelaide Hospital, Adelaide, SA, Australia \\ ${ }^{2}$ Calvary Health Care, North Adelaide Campus, North Adelaide, SA, Australia
}

Lumbar degenerative disc disease is extremely common. Current evidence supports surgery in carefully selected patients who have failed non-operative treatment and do not exhibit any substantial psychosocial overlay. Fusion surgery employing the correct grafting and stabilization techniques has long-term results demonstrating successful clinical outcomes. However, the best approach for fusion remains debatable. There is some evidence supporting the more complex, technically demanding and higher risk interbody fusion techniques for the younger, active patients or patients with a higher risk of non-union. Lumbar disc arthroplasty and hybrid techniques are still relatively novel procedures despite promising short-term and mid-term outcomes. Long-term studies demonstrating superiority over fusion are required before these techniques may be recommended to replace fusion as the gold standard. Novel stem cell approaches combined with tissue engineering therapies continue to be developed in expectation of improving clinical outcomes. Results with appropriate follow-up are not yet available to indicate if such techniques are safe, cost-effective and reliable in the long-term.

Keywords: Low back pain; Disc degeneration; Lumbar fusion; Disc replacement; outcome

\section{Introduction}

Lumbar back pain affects $70 \%-85 \%$ of individuals during their lifetime [1]. The prevalence of back pain increases with age and lifetime recurrence is as high as $85 \%$ [2] with chronic low back pain (LBP) being the most common cause of disability in patients between 45 and 65 years of age [3]. Multiple factors may be relevant for the onset of LBP including degenerative disc disease (DDD), facet arthropathy, disc herniation, spondylolysis and spondylolisthesis. Isolating a single cause is difficult and often multiple morbidities co-exist contributing to the patient's symptoms, as after all, most of these conditions share a common underlying process-degeneration.

Establishing a diagnosis of primary discogenic spinal pain is critical in successfully targeting surgical intervention. LBP, in fact, may be accompanied by radicular symptoms due to central or foraminal stenosis. This paper focuses on the surgical treatment of symptomatic lumbar degenerative disc disease (LDDD), a controversial entity which may not be, in philosophical terms, distinguishable from age-related and genetically predetermined changes that affect the intervertebral disc of the human race.

LDDD is a multifactorial process with changes in disc architecture and integrity, which may lead to pain through abnormal motion of the involved segment. Specifically, abnormal stresses, either through disturbances in oxygenation, nutrition, microvasculature and/or inflammation and collagenase release are thought to contribute to disc dehydration, annular tears and loss of disc height [4].

Received Feb 9, 2016; Accepted Mar 15, 2016

Corresponding author: Mario Giuseppe Tedesco Zotti

Spinal Surgery Unit, Department of Orthopaedics and Trauma, Royal Adelaide Hospital, Adelaide, SA, Australia

Tel: +61-8-8222-4000, Fax: +61-8-8222-2751, E-mail: mariozotti@gmail.com 
These processes are not only thought to incite a neuroinflammatory response that stimulates peptide containing nociceptive fibres [5] but also cause increased innervation to the inner annulus and nucleus pulposus with increased stimulation of segmental dorsal root ganglions (via sinuvertebral nerves) and paravertebral sympathetic fibres (Fig. 1) [6-8]. The loss of disc integrity and shock absorption capability from a dysfunctional disc is also thought to concurrently increase the biomechanical stress upon the facet joints [9]. LDDD is often accompanied by facet related pain due to facet hypertrophy, osteophyte formation, distortion of innervating elements and pathological motion within the facet capsule. Contributing to the pathogenesis and potentially altering the natural history of disc degeneration are several patient factors which may act as confounders in studies comparing different treatments. These include age, gender, genetics, smoking, cardiovascular disease, obesity, physical inactivity, occupational factors (repetitive heavy lifting and vibration), constitutional annulus weakness, low-grade discitis, spinal instability and malalignment $[4,9]$. Age related degeneration, in particular, might be impossible to discriminate from adjacent segment degeneration (ASD) postoperatively [10-12].

\section{Clinical Presentation}

Low back pain (lumbago) generally manifests itself as prevalent axial lumbar back pain with radiation to the

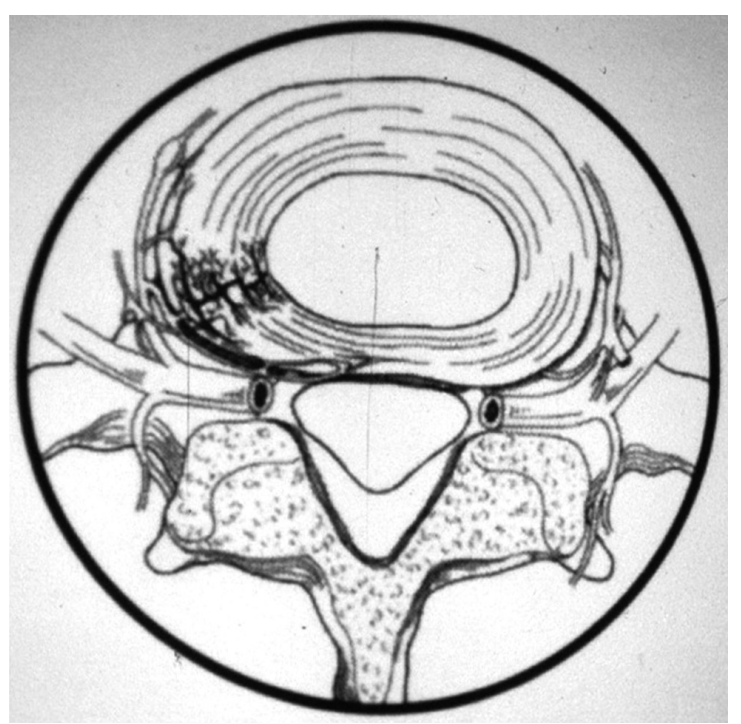

Fig. 1. A schematic demonstrating nerve ingrowth of sinuvertebral nerves into the outer annulus, a process that is increased and upregulated in the case of degenerative disc disease. buttock region. Groin pain [13] and thigh pain [14] have also been described as potential areas of referred pain from the lower lumbar discs. Radicular symptoms suggest concurrent central or foraminal stenosis. A thorough history should be obtained to exclude 'red flags' such as a history of recent trauma, weight loss, night sweats, night pain and fever. On physical examination, lumbar range of motion may also be reduced. The pain is typically worsened with activities that increase intradiscal pressure such as forward flexion, coughing, sneezing and mechanical loading (e.g., lifting from a position of lumbar flexion with weight in front of the body) and is reduced with extension and lying down. Pain and stiffness related to sitting or standing for prolonged periods is common. Pain becoming worse with extension, however, is more likely to be due to facet arthropathy, which may be primary or secondary to disc degeneration.

The natural history of discogenic back pain is that up to $90 \%$ of patients will experience improvement of their symptoms within 6 weeks and resolution by 3 months with or without treatment [15] and approximately $20 \%$ experience recurrence of pain within 6 months [16]. Hence, the initial treatment for discogenic back pain should strictly involve non-operative care prior to referral to a surgeon. Exercise currently represents the main component of a non-operative care program, focusing on core muscles strengthening together with mobilization techniques under supervision, including extension exercises as well as hamstring and pelvic motion orientated programs [17].

\section{Imaging}

Plain radiographs in patients with LDDD may demonstrate reduced disc height and in later stages, end plate sclerosis, osteophyte formation and foraminal stenosis. Magnetic resonance imaging (MRI) is the investigation of choice and, when symptoms persists over a number of months, MRI may show reduced disc height, and disc signal changes consistent with degeneration (reduced signal on a T2-weighted image). MRI may also assist in assessing other causes of lumbar back pain such as facet degeneration, an infection or a tumour. While MRI has high sensitivity in diagnosing LDDD, degenerative disc changes are commonly seen with MRI in asymptomatic patients [12,18]. However, a disc of normal dimensions, position and signal appearance on MRI is unlikely to be a substantial pain generator and should prompt a search for 
other causes of back pain including extraspinal factors.

Preoperative MRI assessment can be suggestive but not diagnostic of LDDD (Fig. 2). Disc pathology itself is most commonly classified on T2-weighted MRI according to the modified Pfirrman et al. [19] classification, which is based upon appearance of structure, distinction of nucleus and annulus, signal intensity and height. Modic et al. [20] proposed a classification system to describe degenerative vertebral endplate and subchondral marrow changes on MRI and in keeping with stages of LDDD. Three types of changes were described with this system: (1) Type I changes with hypointense T1-weighted imaging (T1) and hyperintense T2-weighted imaging (T2) representing marrow oedema and inflammation; (2) Type II changes with hyperintense $\mathrm{T} 1$ and isointense $\mathrm{T} 2$ as normal red marrow is replaced by yellow fatty marrow as a result of marrow ischemia; and (3) Type III changes with hypointense T1 and T2 representing subchondral sclerosis. Modic changes are frequently seen in patients with LDDD, and their presence has been reported as more frequently associated with clinical symptoms [21]. Among the these three types, Type I has been thought to be more strongly associated with LBP [21]. Further MRI parameters have been reported to be correlated with in vivo biochemical

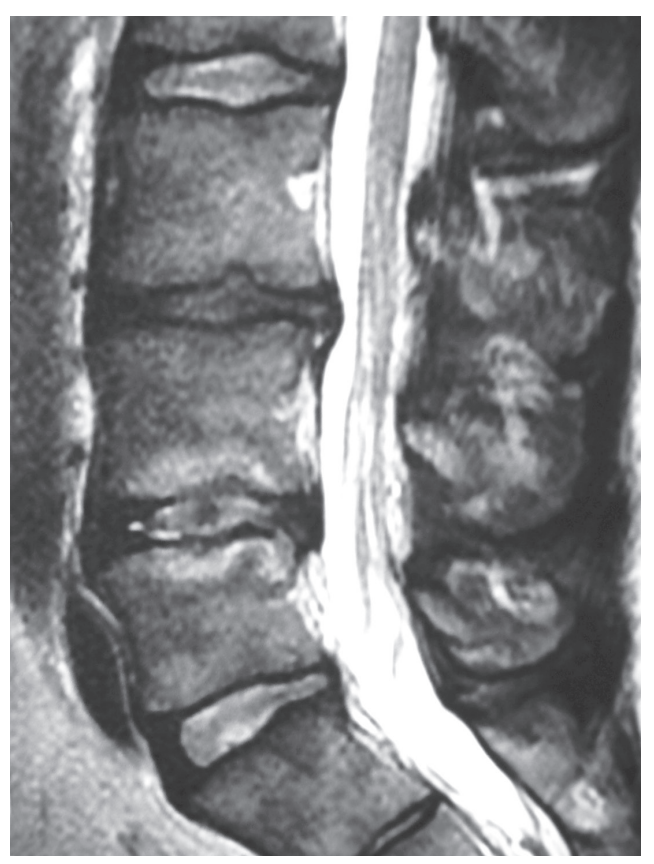

Fig. 2. Sagittal T2-weighted magnetic resonance imaging demonstrating Modic hyperintense end plate changes with increased signal in annulus of a lumbar disc seen in degenerative disc disease. changes, consistent with painful LDDD, including the high intensity zone in the posterior annulus on T2 weighted MRI [22]. While MRI can image the internal morphology of the intervertebral disc, Zhou and Abdi [23] reported that relative low sensitivity (26.7\% to $59 \%)$ as well as high false-positive $(24 \%)$ and false-negative (38\%) rates decrease the value of MRI in screening for the existence of internal disc disruption as a cause for discogenic LBP.

Discography has been utilised to confirm the clinical diagnosis of symptomatic LDDD via assessment for the presence of disruption of internal structure and reproduction of the patient's typical pain. To be diagnostic for LDDD, injection of contrast into an abnormal disc must reproduce the patient's typical symptoms at low pressure/volume, and symptoms should not be reproduced in adjacent normal discs at low pressure. Abnormal disc morphology such as dye extravasation from the injected annulus site indicates annular disruption, which may be interpreted as a positive finding (Fig. 3). However, typical pain reproduction is essential in classifying the discogram as positive. While the literature has mixed reports, some authors report that positive relief at provocative discography, with or without supporting MRI indicative of LDDD, is predictive of superior results for discogenic pain targeted lumbar fusion compared to patients with negative discography [24-26], and conversely, discography has the potential to be suggestive of those that may not benefit from surgical treatment targeted at LDDD [27-29].

Ideally, discography should be performed by an experienced "third party" and not upon patients with significant premorbid psychological conditions or secondary gain issues; this is to increase the independence and interpretive power of the test. In addition, discography should be carried out only for individuals deemed to be candidates for surgical intervention. Although many significant limitations of this technique have been proposed, fusion without preoperative discography has been reported as leading to poorer results compared to patients selected with preoperative discography [25,27]. With preoperative discography, it has shown to profoundly alter decision making (in as much as $71 \%$ of cases) with regard to the segments fused and the decision for surgery [30]. Nevertheless, the popularity of the technique has decreased over the years. Carragee et al. [31] highlighted the issue of iatrogenic degenerative changes from testing "healthy" control discs required for concordant testing, and drew attention to the significant influence of psychosocial overlay and second- 

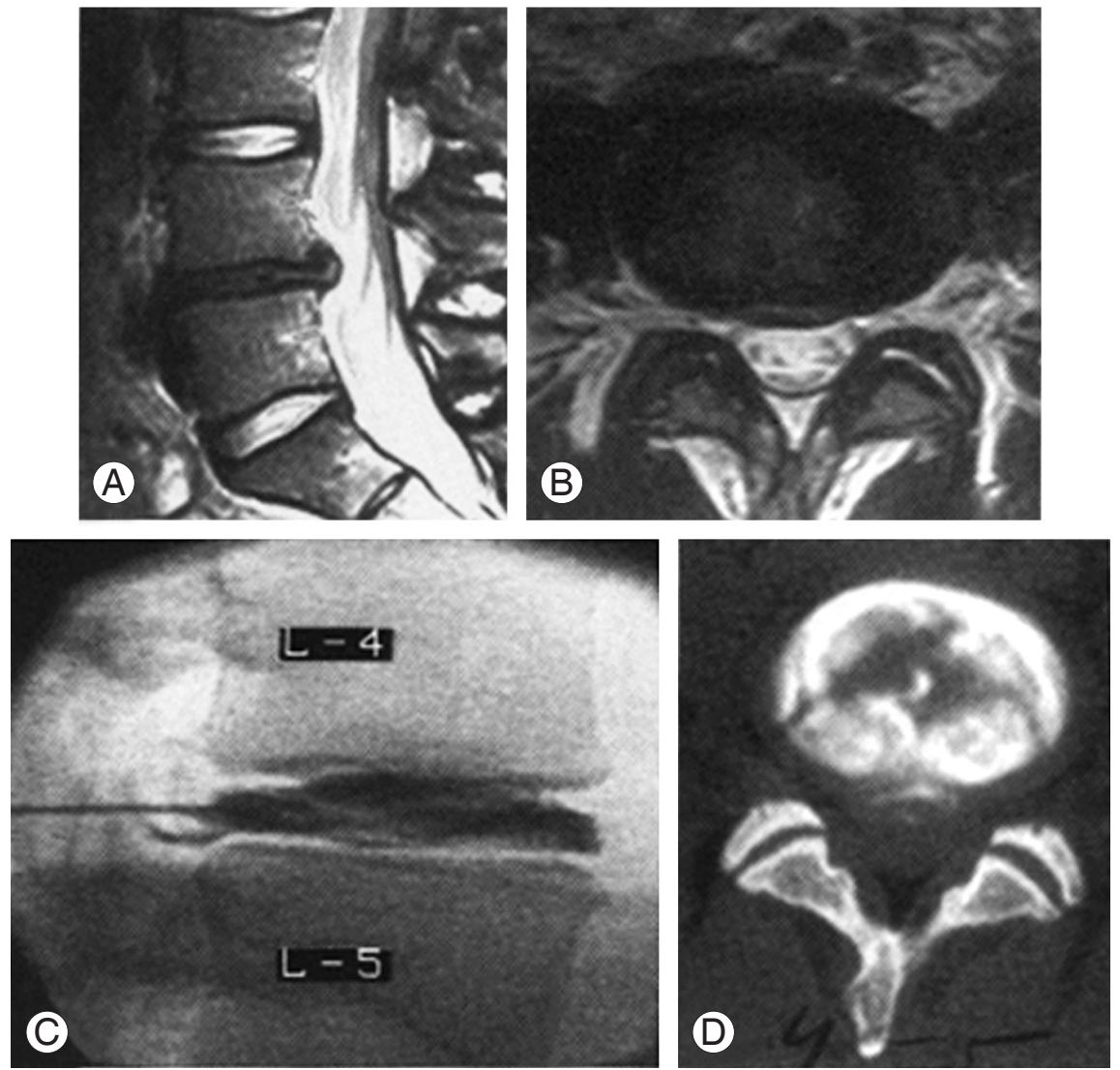

Fig. 3. Sagittal (A) and axial (B) lumbar magnetic resonance imaging demonstrating degenerative disc disease affecting the $L 4 / 5$ intervertebral disc, subsequently assessed with discography (C). There is dye extravasation and evidence of internal disruption of the disc (D).

ary gains in false positive results. However, confusion still exists, with high sensitivity and specificity [32], high likelihood ratios $[33,34]$ and low false positive rates found in selected studies [35] which may be related to the technique using a pain-free control disc and volume related pressure [36].

Diskoblocks using plain local anaesthetic have recently been reported to be a valuable adjunct in the preoperative assessment of patients with prevalent back pain and are thought to be predictive of satisfactory results, possibly representing an alternative diagnostic strategy to discography [37]. Some authors have found a positive correlation between pain relief from a local anaesthetic injection into the discs and contrast leakage from discography [38]. The issue of a possible cause and effect by diskoblocks for the disc has been dismissed as no radiologic indications were seen from a study seen at 5 years for any accelerated degenerative changes from injection of bupivacaine into the control discs of subjects [39]. This led to some groups previously reliant upon discography for preoperative assessment to transition to a preoperative diskoblock strategy [40].

\section{Operative Treatment}

Operative treatment for lumbar back pain has long been a topic of debate with regards to its merits over nonsurgical treatments. The Swedish Lumbar Spine Study Group (SLSSG) provided the first systematic evidence that fusion for DDD resulted in superior outcomes when compared to non-surgical treatments [1]. The operative group, in fact, had a 33\% reduction in back pain score and a $25 \%$ decrease in disability measured using the Oswestry disability index (ODI) whilst the non-surgical group had $7 \%$ and $3 \%$ reductions in pain, respectively. The SLSSG also reported a lower total economic cost in the operative group when compared to long-term non-operative care [2]. Almost twice as many patients returned to work when fusion was carried out, a fact that has ramifications beyond the health economics alone [2]. There has subsequently been more evidence from randomized controlled 
trials to support fusion surgery for pain relief in prevalent back pain with improvement in function in patients not responding to non-surgical treatments $[41,42]$.

Important to both the arthroplasty and fusion techniques is the concept of ASD, thought to be due to the spinal motion segment behaviour changes leading to altered physiological loads. ASD is a radiographic observation of long-term degenerative changes at mobile segments above or below a fused spine. Although such changes are multifactorial, the altered biomechanical stresses are thought to play a key role in development of ASD $[43,44]$. Therefore, there may be an advantage in motion-sparing arthroplasty techniques, as the use of instrumented fusion is thought to increase the risk of ASD compared to non-instrumented fusion; this is presumably due to the rigidity caused by instrumentation as with literature demonstrating a trend towards lower prevalence of ASD with motion-sparing techniques [45].

It has, however, been shown that ASD is not the result of segmental stiffness alone; there are other contributing factors such as the type of approach (anterior-based approaches showing lower rates of ASD compared to the posterior-based ones [46]), sagittal alignment, and in addition surgical and patient factors. As an example, placement of superior pedicle screws can potentially damage the inferior facet of the adjacent segment above, accelerating the onset of ASD. Other factors influencing onset of ASD are age preference (where younger patients were often selected for motion preservation thus introducing a bias), damage to the posterior ligamentous complex, the level fused (more proximal levels have higher rates of ASD compared to distal), facet joint orientation and tropism and, importantly, sagittal imbalance [43,47-50]. Harrop et al. [51] contrasted ASD, which they described as the radiographic finding of degeneration at the level adjacent to the fusion, to adjacent segment disease, which is a clinical symptomatic degeneration, often resulting in additional surgery. Whilst radiographic findings of ASD are very common and approaching $100 \%$, symptomatic adjacent segment disease, a combined clinical and radiographic diagnosis, is said to be less frequent with an incidence ranging between $5 \%$ and $18 \%$ [52].

\section{Fusion for LDDD}

The rationale behind arthrodesis of a selected lumbar spinal segment is to reduce the nociceptive load by wide removal of the disrupted disc material and the stabilization of the affected motion segment(s) that are thought to be causing pain due to continued motion of the involved sensitized levels. Broadly, as a technique, it has long been considered the "gold standard" for LDDD regardless of the approach employed due to its relatively reliable results in properly selected patients. There are three main fusion techniques currently employed, namely posterolateral fusion, interbody fusion and combined interbody fusion with posterolateral fusion, also known as a 360 degree or circumferential fusion.

\section{Posterolateral fusion}

Posterolateral fusion (PLF) targets only the posterior elements. Through a midline skin incision with either a posterior approach or bilateral muscle splitting fascial incisions, facets joints and transverse processes bilaterally are decorticated. Local or autologous bone graft from the iliac crest can be packed into the posterolateral gutters to promote fusion. Historically, posterolateral fusion was performed without instrumentation, but due to the relatively high non-fusion rate $[48,49]$, pedicle screws instrumentation has become standard. Fusion rates have in fact been reported as ranging from 46 to $100 \%$ and the pseudoarthrosis rate have been reported as high as $32 \%$ for noninstrumented fusion [26]. Current evidence supports the use of instrumentation to ultimately increase fusion rates $[48,49]$. However, the evidence of an improved functional outcome for an instrumented fusion instead of a non-instrumented one remains very limited $[48,49]$. A few small clinical trials have shown improved clinical functional outcomes and better fusion rate amongst instrumented patients compared to those with non-instrumented fusion $[47,53]$. However, other studies have suggested no clinical benefit $[48,54]$. It should be noted that not all pseudoarthrosis results may be painful or unstable [49] and therefore, they may not necessarily warrant revision surgery.

In search of better outcomes, spinal surgeons have switched their attention back to the disc, postulating it as the main pain generator. Weatherley et al. [55] investigated a subgroup of patients who had solid posterior fusion with persistent LBP reproduced by provocative discography. These patients experienced relief of the symptoms following subtotal disc clearance and anterior interbody fusion demonstrating the importance of disc clearance and interbody fusion. 


\section{Interbody fusion}

Interbody fusion can be performed with either a posterior or anterior approach. Interbody fusion techniques offer several biologic and biomechanical advantages over posterolateral fusion: (1) They address the disc as the pain generator in patients with discogenic pain. (2) The anterior column of the spine supports $80 \%$ of the body load and consequently interbody devices are subjected to compressive load. Together with a large surface area, this biomechanical advantage facilitates fusion. (3) Insertion of interbody devices allows restoration of intervertebral height, correction of lumbar lordosis and restoration of sagittal balance depending on design and final positioning on the endplates, with potential for indirect decompression of the neural elements.

Various approaches have been described to achieve this purpose: (1) Posterior lumbar interbody fusion (PLIF) accesses both columns (anterior and posterior) through a single posterior approach and involves a wide laminectomy, with partial or complete facetectomy, subtotal discectomy, endplate preparation and insertion of interbody device with or without supplemental pedicle screw instrumentation. This approach allows excellent spinal canal decompression, which can address concurrent central stenosis. The wider the resection, the lesser the neural retraction to access the diseased intervertebral disc, although this approach may destabilize the segment and it is recommended that in order to achieve stability of the construct, pedicle screws be employed especially above L5-S1 and when multiple levels are involved [56]. The disc is approached through the axilla formed by the dural sac and exiting upper nerve root. The interbody device consists of either a cage (typically manufactured from Peek and carbon fibre) or a bone graft spacer, which is then inserted after end plate preparation with curettes and rongeurs. PLIF can also be supplemented with posterolateral fusion to increase fusion rates. (2) Transforaminal lumbar interbody fusion (TLIF) is a modification of the PLIF technique where the intervertebral disc is exposed unilaterally through a transforaminal approach with subtotal facetectomy in conjunction with pedicle screw instrumentation (Fig. 4). Nerve root retraction is required to access the disc, exposing the patient to a risk of nerve injury and radiculitis. Bilateral pedicle screw instrumentation is recommended to restore stability. Similar to PLIF, contralateral posterolateral fusion can be added to increase fusion rates. While some advocates of this procedure maintain that they can treat a wide spectrum of pathologies through this approach, including degenerative spondylolisthesis, a potential disadvantage is that it is a more demanding technique for implantation of the interbody device, which can affect the ability to adequately achieve sufficient lordosis and subtotal disc clearance. (3) The anterior approach for lumbar interbody fusion (ALIF) is performed through either a transperitoneal or retroperitoneal approach. This approach allows access to the lumbar discs from L2 to the sacrum. Renal vessels and the diaphragm limit the more proximal extension of the
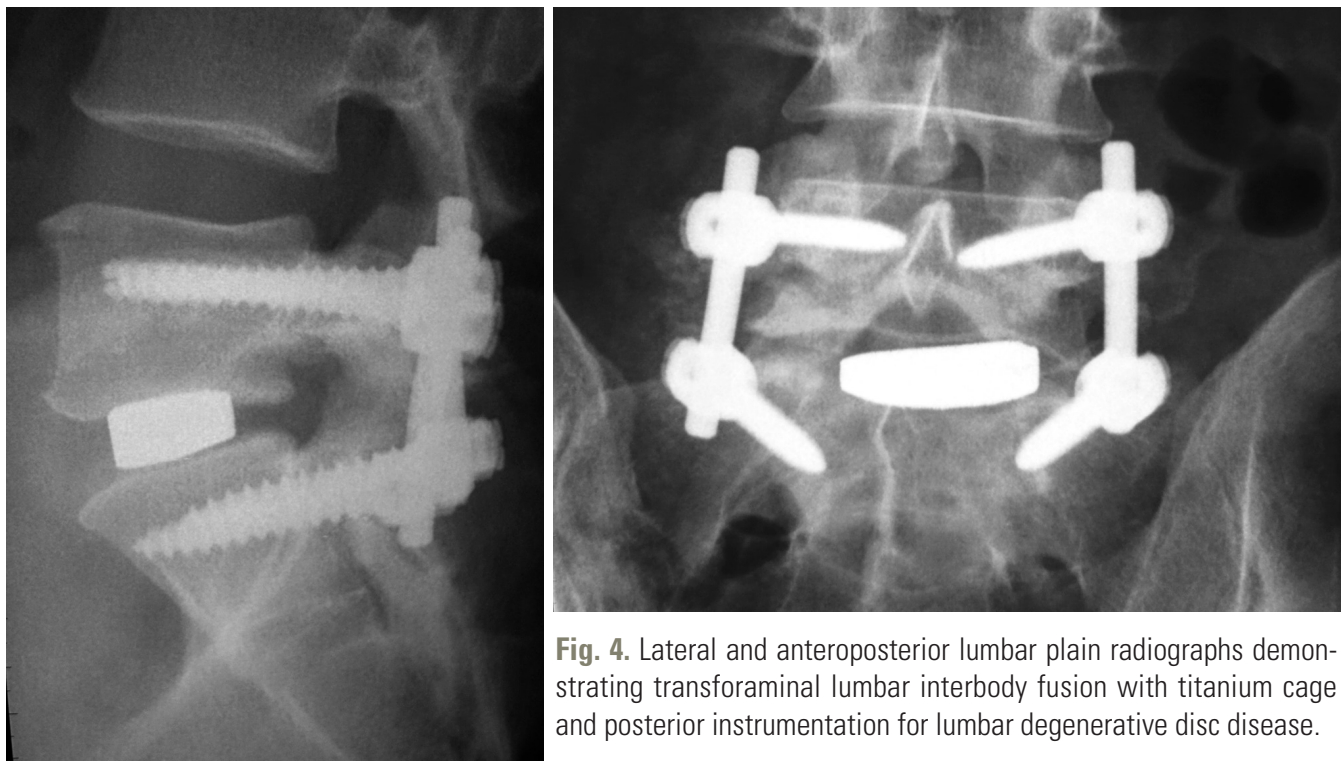

Fig. 4. Lateral and anteroposterior lumbar plain radiographs demonstrating transforaminal lumbar interbody fusion with titanium cage and posterior instrumentation for lumbar degenerative disc disease. 
exposure. The pubic symphysis occasionally also precludes appropriate visualisation and instrumentation of the L5-S1 disc space in patients with a deep-seated L5-S1 level relative to the pelvis. Lateral radiographs including the pubis are obtained during the preoperative planning stages to assess suitability of this approach at that level. Preparation of end plates and insertion of graft or implant are similar to PLIF and TLIF but the direct front-on approach allows better visualization and larger size of implants with greater capacity to increase disc height and lordosis.

\section{Minimally invasive surgery fusion}

The minimally invasive surgery (MIS) fusion techniques have been developed that allow access while limiting soft tissue dissection and muscle damage. These are often modifications of pre-existing open techniques. This is in response to higher patient demand and expectation for faster recovery times in line with minimally invasive technique advances in other areas of surgery in the last three decades. Proponents of MIS interbody fusion techniques have also highlighted reduced intraoperative blood loss and muscle damage $[57,58]$ as well as faster return to work and decreased opioid dependence for the patient [59].

MIS adaptation of TLIF utilises the Wiltse paraspinal approach [60] through multifidus and longissimus intermuscular plane for unilateral facetectomy and pedicle screw instrumentation. This technique reduces muscle stripping, preserves blood supply and muscular attachment and thereby reduces erector muscle dysfunction and fibrosis [61].

More recently lateral lumbar interbody fusion and anterior to psoas approaches have been developed, which are MIS or mini-open in nature. The former technique gains access to the lateral lumbar spine through a transpsoas approach while the latter occurs anterior to psoas [62]. The patient is placed in a lateral decubitus and a small lateral incision is made to gain access through the retroperitoneal space. Neural monitoring is then placed in the posts to identify the lumbosacral plexus. Safe access to the lumbar spine is usually obtained within the anterior one third to one half of the psoas; however, neurologic adverse events overall are reported for $18 \%-40 \%$ of patients [63-65].

\section{Comparison of fusion techniques}

Over the past few decades, there has been an explosion of different instrumentation types, fusion methods and bone graft sources developed to improve fusion rates and improve functional outcomes. Many studies have since been published to establish their utility, but results are often contradictory, with inclusion of a wide range of clinical diagnoses such as isthmic and degenerative spondylolisthesis and differing methods of patient selection that are often uncontrolled for comorbidities such as smoking, diabetes mellitus and steroid use. This makes comparisons difficult when attempting to advocate for one technique over another.

With regards to ALIF, the advantages of include preservation of posterior tension-band functioning musculature, improved access to the intervertebral space for disc removal and precise placement of interbody graft or implant for ease of height and lordosis restoration. The approach has several other advantages such as obviating the need for prone positioning, reduced blood loss (assuming no great vessel injury occurring intraoperatively), reduced neurological injury and adjacent segment disease $[66,67]$. ALIF also allows insertion of a larger structural graft without endangering neural structures. However, it can be technically demanding, particularly in the case of an obese patient and those with widespread atherosclerosis, and requires confidence with dealing with potential vascular complications due to retraction of vessels with a potential for tears to the common iliac and iliolumbar vessels [68]. Furthermore, injury to the parasympathethic plexus may result in retrograde ejaculation and autonomic sensory disturbances in the lower limbs. These disadvantages have led to a movement of surgeons employing the expertise of "access" vascular surgeons and intraoperative heparin administration to facilitate access to the intervertebral disc in the hope of reducing complications for the patient [68-70]. Bateman et al. [71] undertook a systematic review of the complication of anterior approach surgery finding intraoperative and postoperative complication rates of $9.1 \%$ and $5.2 \%$, respectively. The most common complications reported were venous injury (3.2\%), retrograde ejaculation $(2.7 \%)$, neurologic injury (2\%), prosthesis related (2\%), postoperative ileus (1.4\%), superficial infection (1\%), and others (1.3\%). In addition, should an ALIF technique be considered for a candidate with poorer bone stock or previous wide laminectomies, this would be a relative indication for supplemental posterior instrumentation or posterolateral fusion compared to a standalone procedure. 
Early experience with ALIF as a standalone procedure was associated with high rates of non-union [72], but reports on newer techniques and devices designed for ALIF have shown good clinical outcomes and comparable fusion rates with other techniques [73] as well as comparable biomechanical properties to the addition of posterior instrumentation (Fig. 5) [74]. ALIF combined with posterolateral-instrumented fusion or also known as circumferential fusion provides the best fusion rates; however, this involves intraoperative repositioning of the patient and the added morbidity of increased operative time.

The main theoretical benefit of PLIF and TLIF over ALIF is the significant lower risk of injury to anterior vascular elements. PLIF also allows for simultaneous decompression of central canal and bilateral foraminae. While TLIF allows for only unilateral decompression of foramina compared to PLIF, it may lead to a lower incidence of neural complications (dural tears and epidural fibrosis because of the minimal and unilateral exposure of the cauda equina). PLIF is not recommended for cases involving the upper lumbar level (L1-2) due to the need to manipulate the conus medullaris. While TLIF is considered by some authors as safer to PLIF at this level due to lesser neural retraction, great caution is still required. In a meta-analysis comparing PLIF to TLIF, PLIF was associated with a significantly higher complication rates [75], in particular dural tears and root injury as well as graft
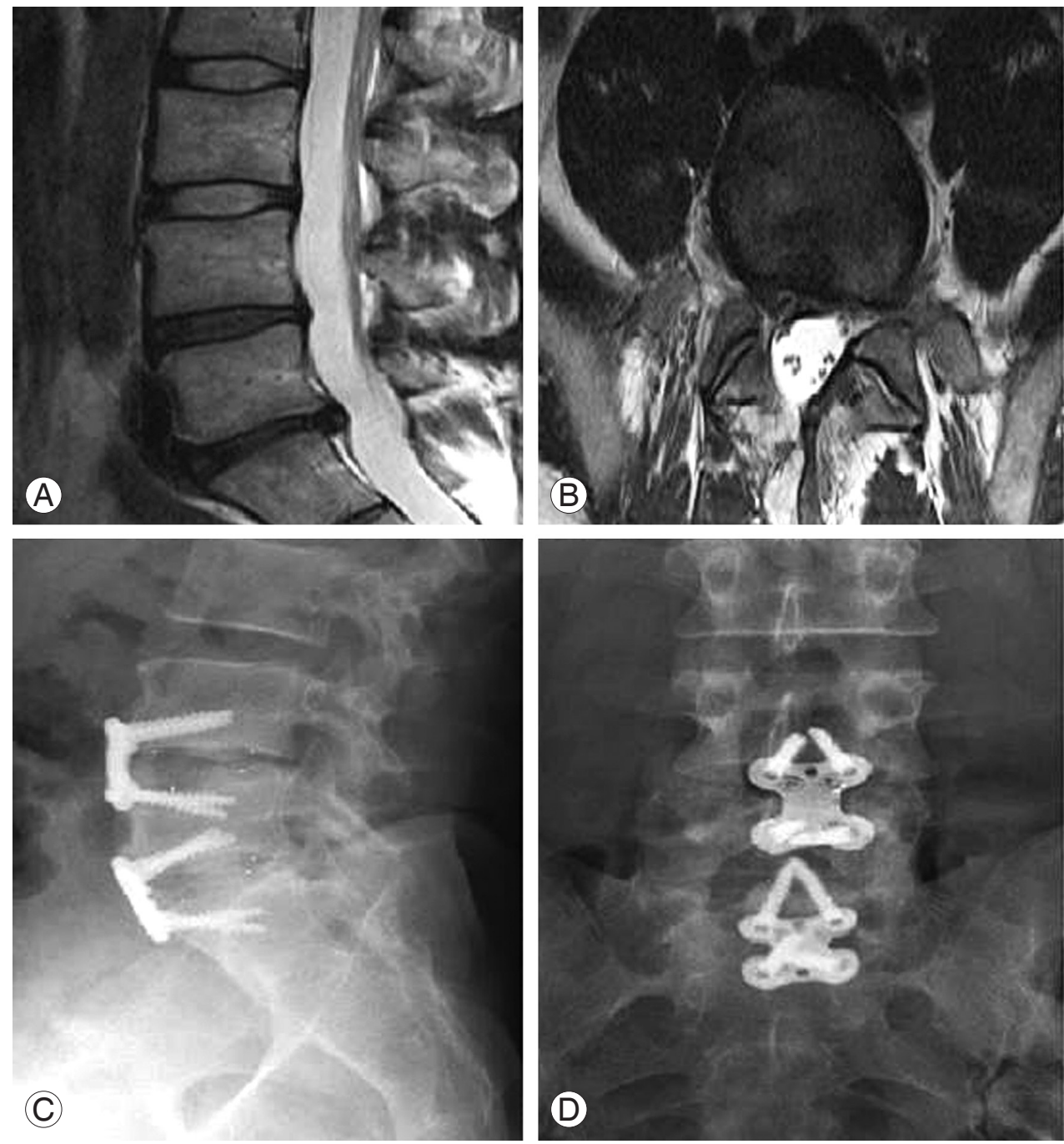

Fig. 5. Preoperative magnetic resonance imaging of a 40-year-old male who had recurrent disc prolapse with radiculopathy following an initial discectomy $(\mathbf{A}, \mathbf{B})$. Postoperative radiographs of anterior lumbar interbody fusion performed for the same patient demonstrating progression of fusion at 6-month follow-up (C, D). 
malposition. However, there were no differences with regards to clinical satisfaction, blood loss and radiographic evidence of fusion between the two groups, even if PLIF required longer operative times.

Unilateral instrumentation has also been advocated as an alternative to bilateral instrumentation for spinal fusion with interbody device. The theoretical advantage is shorter operative times and lower operative costs for implants [76]. In a systematic review of ten randomized trials, Molinari et al. [76] reported no difference in clinical outcomes, union rates nor complications when singlelevel unilateral instrumentation was used for degenerative conditions in the lumbar spine compared to bilateral instrumented fusion with PLIF and TLIF.

When comparing the three main types of fusion techniques-posterolateral, posterolateral with instrumentation, and circumferential-SLSSG found that circumferential fusion had the highest fusion rate, followed by instrumented posterolateral fusion, for all groups having significantly reduced pain and disability and no overall significant differences in clinical outcomes between the groups. The circumferential group, however, had significantly more complications, prolonged operating times and prolonged hospital stays.

The issue of fusion rate needs careful interpretation. Radiological determination of lumbar fusion is known to have poor intra- and inter-observer consistency and depends on the method utilised. Sensitivity and specificity of plain radiographs have been reported to be as low as $43 \%$ and $50 \%$, respectively [48]. Additionally reported fusion rates in the literature can be flawed with bias, as in many cases the designation of fusion status is assigned by the operating surgeon. In addition, fusion rates are not the only measure of success after lumbar spine fusion and indeed some pseudoarthroses (such as the "locked" pseudoarthrosis [77]) are not incompatible with good outcomes.

A randomized controlled study by Videbaek et al. [78] was in contrast to the findings of the Swedish Lumbar Spine Study Group, and reported improved mid-term outcomes with circumferential fusion when compared to instrumented posterolateral fusion alone. In this trial, there was a statistically significant improvement in pain score and functional score with a 5 to 9 year follow up [78]. The study population was significantly younger when compared to the Swedish group with a majority of patients being at work. A further study by Soegaard et al. [79] supported these results, reporting superior cost saving in the circumferential group compared with posterolateral fusion group in the long term.

In line with current evidence, one may suggest choosing interbody fusion techniques in the younger, more active and working individuals and in patients with an increased risk of non-union i.e. smokers. Also, the debate between conventional or minimally invasive techniques will continue until long-term comparisons of these techniques in well-designed studies are available. In order to displace conventional techniques as the standard of care, MIS techniques would need to demonstrate at least equivalent outcomes without additional costs and increased complications, in addition to the currently reported beneficial short term outcomes of reduced hospital time and quicker return to employment [80].

\section{Interbody and graft options}

Previously, tricortical blocks of autologous iliac crest bone graft were used in surgery. This presented substantial technical challenges, including the sizing of the grafts, its stability once impacted into the intervertebral disc space and the issue of subsequent collapse and subsidence. The development of interbody devices with instruments designed for ease of introduction has increased the technical ease of interbody fusion. There is currently a wide range of materials used as interbody devices with which various graft options can be used to enhance fusion. These interbody devices also have design characteristics that may help in restoring lumbar lordosis, sagittal balance, indirect neuroforaminal decompression and physiological load through the anterior spinal column. Titanium cages have over the years been popular but can be associated with subsidence. Interbody cages made of carbon fibre and the non-absorbable, biocompatible material polyetheretherketone (PEEK) are radiolucent and are thought to have a modulus of elasticity closer to bone. These cages may have lower subsidence rates and, in addition, their usage allows easier assessment of fusion rates on radiographs. However, some debate exists on the enhancement by titanium implants for bone incorporation into the implant as opposed to PEEK, which is thought to stimulate fibrous, non-mineralised tissue.

Iliac crest graft has been long been considered the gold standard for spinal fusion, but it has several disadvantages compared to currently available alternatives. These include 
associated donor site morbidity, increased blood loss, prolonged hospital stay and often limited graft volume in older patients. Bone graft substitutes can be broadly classified into two categories: (1) There are osteoinductive agents that induce formation of bone, and these include agents such as recombinant human bone morphogenetic protein, bone marrow aspirate etc. (2) There are also osteoconductive agents, including demineralized bone matrix, tricalcium phosphate etc., that provide a scaffold for new bone growth.

Allograft yields comparable fusion rates to autograft without donor site morbidity [81], but with an increased cost and a potential for infectious disease transmission. Demineralised bone matrix (DBM), while still on-going investigation regarding its efficacy, has had early positive reports with high fusion rates [82]. Currently DBM is used as mass extender, combined with local autologous bone graft, rather than used in isolation. Bone morphogenetic proteins (BMPs) are reported to be at least as effective as autologous bone graft substitutes or extenders [83]; however, there are concerns regarding their safety. With BMPs, extensive osteolysis resulting in graft subsidence and cage migration has been reported [84]. Higher rates of retrograde ejaculation have also been reported when used in ALIF, thought to be due to the inflammatory response associated with release of cytokines due to BMP in closed vicinity of the parasympathetic plexus [85]. However, Scott-Young [86] reported the incidence of the above to be only $0.7 \%$ in a large cohort of males who underwent ALIF and similarly another study did not find the high rates of complication previously reported [87]. Although not proven, there are theoretical concerns for a cancer when applying exogenous transforming growth factors such as BMPs [88]. A multitude of other graft substitutes and biological mediators are being introduced into clinical practice, but are beyond the scope of this review.

\section{Lumbar disc arthroplasty}

Lumbar disc arthroplasty (LDA) has been increasingly adopted into routine spinal practice since its introduction in 1966 [89]. After a lag period, the Charité Hospital in Berlin, East Germany led the trend for widespread implantation beginning in the 1980s. LDA typically is performed through an anterior approach at lower lumbar levels (L4/5 and L5/S1) in younger and active individuals with limited ASD, adequate bone stock, absence of spon- dylolisthesis and normal facet joints (Fig. 6). Non-inferiority studies involving both cohorts of patients implanted with the Charite prosthesis compared to ALIF [90], the ProDisc prosthesis compared against circumferential fusion [91] and the Maverick compared to ALIF [92], respectively, showed favourable results for LDA but each had methodological flaws. There is no current conclusive evidence of LDA superiority in the long-term in level I studies and the surgery is technically more challenging. However, mid-term studies of LDA have reported satisfactory clinical results and implant survival and comparable complication profiles to fusion $[93,94]$ with proponents of LDA supporting its use for several theoretical and clinical advantages.

The major driver for development of this technique has been the motion preserving philosophy as an alternative to fusion with theoretically lower risk for ASD. European studies have cited rates of ASD at 10-year follow-up of LDA to be $2.0 \%-2.8 \%$ and up to $4.5 \%$ in a large North American study [95], which compares favourably to historical rates in lumbar fusion of between 14 and $29 \%$. However, it may be unfair to compare ASD to fusion procedures indiscriminately as the anterior approach itself has been reported as being associated with lower rates of ASD $[96,97]$.

Other advantages cited for LDA include having no need either for grafting or screw based fixation [98] and having a lower reoperation rate with at least equivalent rates of return to work and clinical outcomes to fusion at mid-term [99]. In one study, David [100] concluded that the "rate of reoperation secondary to adjacent segment disease is ten times lower than the rates reported in the literature for fusion." Furthermore, the rates of secondary sacroiliac joint dysfunction following LDA were low in the mid-term [101]. Studies of modern LDAs have also reported faster patient recovery, higher satisfaction in the short-term compared to the fusion techniques [95]. Patient satisfaction rates have been in the order of $88 \%$ or more $[90,102,103]$, at least equivalent to fusion satisfaction rates quoted as $85 \%-95 \%$ [104,105], although some series have reported a mild but statistically significant deterioration in outcomes of patients transitioning from early to mid-term follow-up [94]. High rates of return to work and lower long-term unemployment have also been reported as other benefits for the LDAs [90]. These results may also be further improved with focused physiotherapy [106]. 

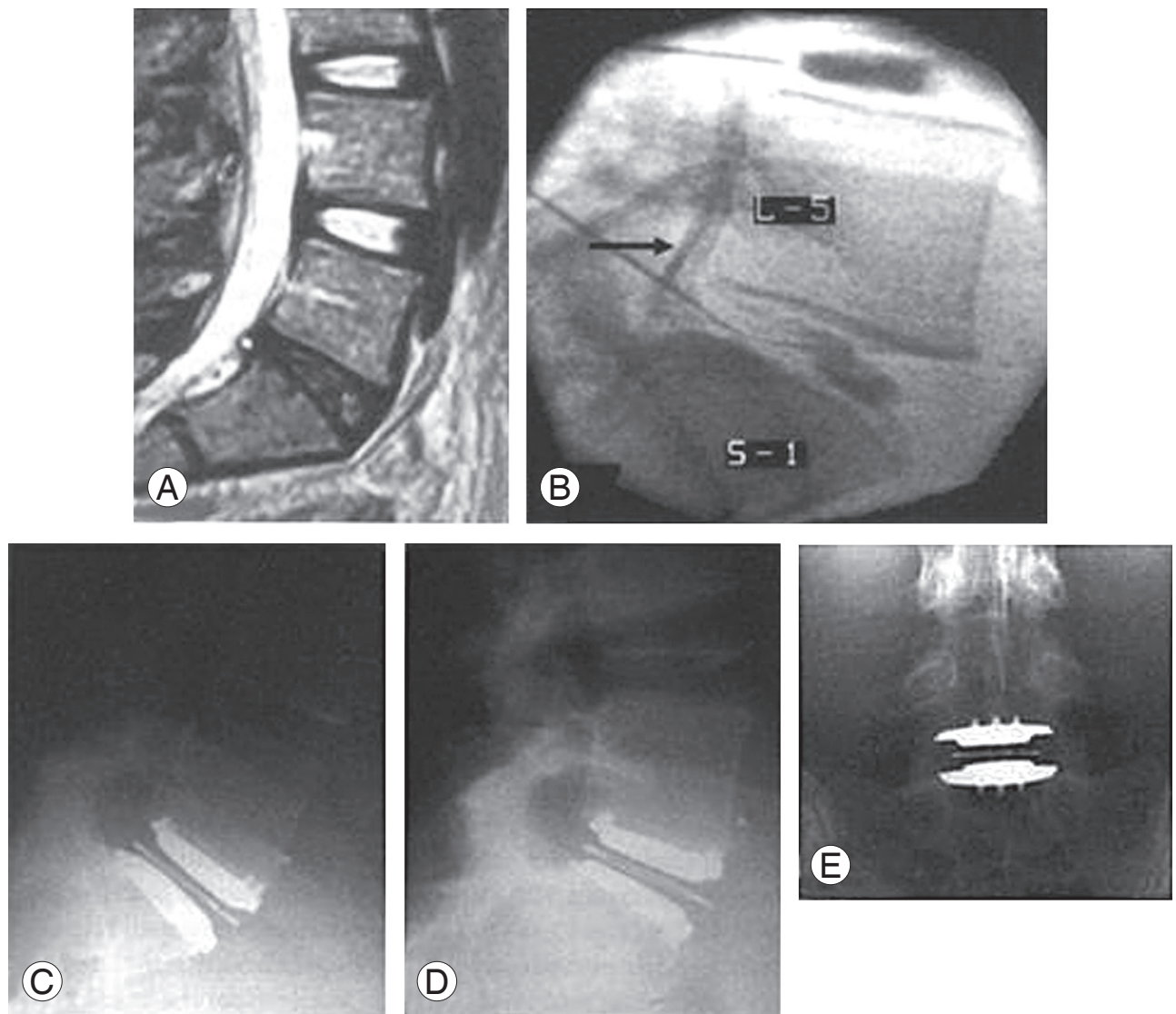

Fig. 6. Preoperative magnetic resonance imaging (MRI) of a 42-year-old woman with chronic axial low back pain with evidence of degenerative disc disease on $\mathrm{MRI}(\mathbf{A})$ and concordant reproduction of symptoms of provocative discography (B). Postoperative radiographs demonstrating lumbar disc arthroplasty with flexion and extension (C, D) as well as anteroposterior views (E).

Disadvantages cited in the literature are the disappointing outcomes from some of the earlier designs (perhaps confounded also by patient selection), the lack of longterm outcomes of modern designs, the lower versatility in indications compared to fusion and the difficulty in acquiring adequate surgical expertise in performing this procedure. Many of the cited complications such as implant extrusion and vascular injury can be linked to inadequate training, improper sizing and lack of confirmation of satisfactory placement on imaging [107] with implant impingement linked to the aforementioned factors [108]. Design variables relating to constraint and core mobility have also been shown to alter wear and force transmission in in vitro studies $[109,110]$.

Earlier, some of the initial LDA designs led to inconsistent outcomes [111]. For example, the cumulative survival for the Acroflex LDA was only $60.7 \%$ at 10 years when first revision surgery was used as the end point. Etiology of the implant failure reported by authors [112] included failure of osteointergration, midsubstance elastomeric tears and osteolysis. Complication rates, while reported to be lower than fusion in the Charité trials $(29.1 \%$ for arthroplasty and $50.2 \%$ for fusion at 2-year follow-up), are still significant [113]. These can be broadly separated into those related to the anterior surgical approach (e.g., vascular injury, nerve root injury, retrograde ejaculation), prosthesis/fusion failure (e.g., subsidence, osteolysis, migration, implant fracture, endplate fracture, pseudoarthrosis), heterotopic ossification (up to $76 \%$ at 3 years) and subsequent hypomobility of the implant and donorsite complications [93]. Device failures necessitating repeat operations have been reported at $5.4 \%$ to $6.3 \%$. Salvage procedures involving conversion to spinal fusion are technically demanding; however, they appear to improve outcomes modestly in failed LDA [112]. Earlier designs were also associated with a high rate, in the order of $60 \%$, 
of spontaneous fusion in the long term [111]. Metal ion and polyethylene wear particle release from the articulation interface also add to the disadvantages [114]. Limited versatility exists compared to fusion techniques as there are relative contraindications for three or more lumbar levels, high lumbar disease (above L3), spondylolisthesis, severe ligamentous instability, facet degeneration, adjacent prior fusion and conditions affecting bony healing (e.g. rheumatoid arthritis, diabetes mellitus and steroid use) $[115,116]$.

\section{Multiple-level LDA and Hybrid LDA/Fusion Techniques}

Despite good results for single-level LDA, there is evidence to suggest that the two-level arthroplasty constructs have comparatively poorer outcomes and have an increase in the rate of complications compared to the two-level fusions $[94,117,118]$. However, conflicting data exists with some authors reporting good outcomes with two-level LDA [119] and outcomes comparable to single-level LDA $[117,120,121]$, and thus calling into question the role of design and constraint of the implant itself [122,123]. The poorer outcomes were in fact thought to be due to increased segmental instability and postoperative facet and sacroiliac pain from increased loading [94].

Some authors have proposed hybrid constructs of LDA/ ALIF in addressing multilevel disease in the lumbar spine, and combining the perceived advantages of motion-sparing and fusion techniques (Fig. 7). However, there are currently limited published results in this area. This approach currently has only been reportedly used for two-level disease in the literature, with ALIF performed on the more severe (usually inferior) level and LDA on the less severely affected or hypermobile level. Hoff et al. [124] reported results of a randomized trial of ALIF and LDA compared with circumferential fusion using TLIF posteriorly with a mean of 37 months follow-up. The hybrid group was associated with a lower VAS with and superior lordosis at the lower lumbar levels as well as having comparatively increased range of motion at the L4/5 level with a similar low complication profile and overall Similarly, Aunoble et al. [125] published their experience in 42 patients over 2 years follow-up and showed a 53\% improvement in the functional score and a $65 \%$ improvement in the visual analogue score. For the same group of patients, however, symptoms derived from parasympathetic changes were

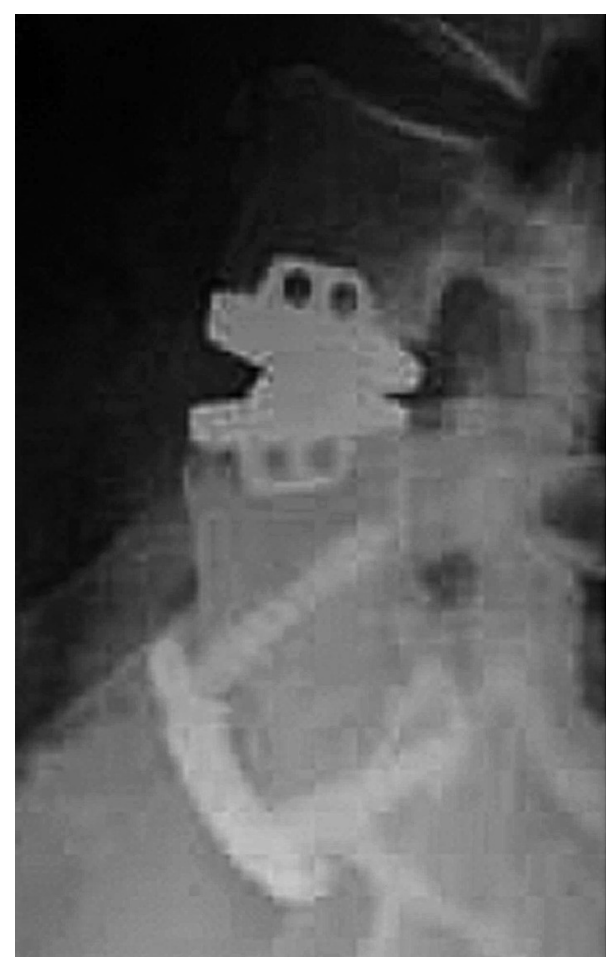

Fig. 7. A hybrid lumbar disc arthroplasty/approach for lumbar interbody fusion construct performed for treatment of two-level disc disease in a 46-year-old female.

noted in only 9.5\%. Kasis et al. [126] additionally presented improvement in all outcome parameters at minimum 2 years follow-up with a low complication rate. Long-term studies are required in this area to assess viability of this technique in addressing multiple-level LDDD and, specifically, to assess whether these techniques are superior clinically to multiple-level fusion. This would need assessing not just the clinical outcomes but also the complication profiles, ASD, revision rates and economic costs.

\section{Novel technologies}

Stem cell therapy combined with tissue engineering approaches for effective delivery into the degenerative disc has been proposed as a minimally invasive alternative to manage LBP. This therapy focuses on the restoration of extracellular matrix of the "damaged" disc where autologous nucleus pulposus cells or bone marrow derived mesenchymal stem cells are harvested, expanded in vitro and delivered into the nucleus pulposus, with the hope of stabilizing or reversing LDDD pathology. In a recent systematic review evaluating the effectiveness of a tissue 
engineered approach in the treatment of DDD in controlled animal studies, the technique has shown promising results in improvement in disc height and MRI signal intensity but none of the studies showed restoration to the properties of a healthy disc [127]. Human trials on the use of mesenchymal stem cells from autologous bone marrow in patients with LDDD are currently on-going in multiple centres. Finally, short term results of intradiscal pulsed radiofrequency have been promising and have shown not to be significantly different from intradiscal electrothermal therapy at 6 months [128]. Results with appropriate follow-up are not yet available to indicate if such techniques are safe, cost-effective and reliable in the long-term.

\section{Conclusions}

While LDDD is extremely common, the role of operative treatment and the choices of which operative treatments to select for which patients remain controversial. There is scientific evidence to support surgery in carefully selected patients who have failed to respond to appropriate non-operative treatments over a minimum of six months and do not exhibit any substantial psychosocial overlay. Confirming a clinical diagnosis of discogenic back pain with supportive imaging is, however, crucial for targeted treatment of the condition with either disc clearance and fusion or LDA.

LDA for LDDD is still a relatively novel procedure despite promising mid-term outcomes. As revision procedures for LDA can be complex with expenses considerable, long-term studies demonstrating superiority over fusion are required before this technique may be recommended to replace fusion as the gold standard. While early evidence suggests comparable results between single-level LDA and fusion, the role of multilevel LDA has not yet been fully scrutinized in comparison to multiple-level fusion. There is no current long-term evidence that motion-sparing LDA reduces symptomatic adjacent segment disease or robust long-term evidence for hybrid techniques combining arthroplasty and fusion. Should multiple-level LDA or hybrid constructs demonstrate long-term evidence in line with their promising short- to mid-term outcomes, they may surpass fusion surgery as the treatment of choice for patients with multilevel LDDD who meet indications for either fusion or LDA.

Novel and minimally invasive fusion techniques continue to be developed in expectation of improving clini- cal outcomes through minimizing soft-tissue damage. However, the only long-term evidence for predictably successful clinical outcomes currently exists in carefully selected patients undergoing open fusions and employing correct grafting and stabilization techniques. As such, the best approach for fusion remains debatable. In addition, the more complex, technically demanding and higher risk interbody fusion techniques, such as ALIF or TLIF, might be advocated for younger, active patients or patients with a higher risk of non-union.

\section{Conflict of Interest}

No potential conflict of interest relevant to this article was reported.

\section{Acknowledgments}

We would like to thank Ass. Prof. Matthew Scott-Young (Gold Coast Spine, Queensland, Australia) for enlightening perspectives on anterior approach surgery and lumbar disc arthroplasty.

\section{References}

1. Fritzell P, Hagg O, Wessberg P, Nordwall A; Swedish Lumbar Spine Study Group. 2001 Volvo Award Winner in Clinical Studies: Lumbar fusion versus nonsurgical treatment for chronic low back pain: a multicenter randomized controlled trial from the Swedish Lumbar Spine Study Group. Spine (Phila Pa 1976) 2001;26:2521-32.

2. Fritzell P, Hagg O, Jonsson D, Nordwall A; Swedish Lumbar Spine Study Group. Cost-effectiveness of lumbar fusion and nonsurgical treatment for chronic low back pain in the Swedish Lumbar Spine Study: a multicenter, randomized, controlled trial from the Swedish Lumbar Spine Study Group. Spine (Phila Pa 1976) 2004;29:421-34.

3. Frank JW, Kerr MS, Brooker AS, et al. Disability resulting from occupational low back pain. Part I: What do we know about primary prevention? A review of the scientific evidence on prevention before disability begins. Spine (Phila Pa 1976) 1996;21:290817.

4. Choi YS. Pathophysiology of degenerative disc disease. Asian Spine J 2009;3:39-44. 
5. Ozawa T, Ohtori S, Inoue G, Aoki Y, Moriya H, Takahashi $\mathrm{K}$. The degenerated lumbar intervertebral disc is innervated primarily by peptide-containing sensory nerve fibers in humans. Spine (Phila Pa 1976) 2006;31:2418-22.

6. Garcia-Cosamalon J, Fernandez-Fernandez J, Gonzalez-Martinez E, et al. Innervation of the intervertebral disc. Neurocirugia (Astur) 2013;24:121-9.

7. Miyagi M, Ishikawa $\mathrm{T}$, Kamoda $\mathrm{H}$, et al. ISSLS prize winner: disc dynamic compression in rats produces long-lasting increases in inflammatory mediators in discs and induces long-lasting nerve injury and regeneration of the afferent fibers innervating discs: a pathomechanism for chronic discogenic low back pain. Spine (Phila Pa 1976) 2012;37:1810-8.

8. Takahashi K, Aoki Y, Ohtori S. Resolving discogenic pain. Eur Spine J 2008;17 Suppl 4:428-31.

9. Yong-Hing K, Kirkaldy-Willis WH. The pathophysiology of degenerative disease of the lumbar spine. Orthop Clin North Am 1983;14:491-504.

10. Boden SD, Davis DO, Dina TS, Patronas NJ, Wiesel SW. Abnormal magnetic-resonance scans of the lumbar spine in asymptomatic subjects: a prospective investigation. J Bone Joint Surg Am 1990;72:403-8.

11. Brinjikji W, Luetmer PH, Comstock B, et al. Systematic literature review of imaging features of spinal degeneration in asymptomatic populations. AJNR Am J Neuroradiol 2015;36:811-6.

12. Matsumoto M, Okada E, Toyama Y, Fujiwara H, Momoshima S, Takahata T. Tandem age-related lumbar and cervical intervertebral disc changes in asymptomatic subjects. Eur Spine J 2013;22:708-13.

13. Oikawa Y, Ohtori S, Koshi T, et al. Lumbar disc degeneration induces persistent groin pain. Spine (Phila Pa 1976) 2012;37:114-8.

14. Laplante BL, Ketchum JM, Saullo TR, DePalma MJ. Multivariable analysis of the relationship between pain referral patterns and the source of chronic low back pain. Pain Physician 2012;15:171-8.

15. Madigan L, Vaccaro AR, Spector LR, Milam RA. Management of symptomatic lumbar degenerative disk disease. J Am Acad Orthop Surg 2009;17:10211.

16. Cassidy JD, Cote P, Carroll LJ, Kristman V. Incidence and course of low back pain episodes in the general population. Spine (Phila Pa 1976) 2005;30:2817-23.

17. van Tulder MW, Malmivaara A, Esmail R, Koes BW.
Exercise therapy for low back pain. Cochrane Database Syst Rev 2000;(2):CD000335.

18. Nakashima H, Yukawa Y, Suda K, Yamagata M, Ueta T, Kato F. Abnormal findings on magnetic resonance images of the cervical spines in 1211 asymptomatic subjects. Spine (Phila Pa 1976) 2015;40:392-8.

19. Pfirrmann CW, Metzdorf A, Zanetti M, Hodler J, Boos N. Magnetic resonance classification of lumbar intervertebral disc degeneration. Spine (Phila $\mathrm{Pa}$ 1976) 2001;26:1873-8.

20. Modic MT, Steinberg PM, Ross JS, Masaryk TJ, Carter JR. Degenerative disk disease: assessment of changes in vertebral body marrow with MR imaging. Radiology 1988;166(1 Pt 1):193-9.

21. Jensen TS, Karppinen J, Sorensen JS, Niinimaki J, Leboeuf-Yde C. Vertebral endplate signal changes (Modic change): a systematic literature review of prevalence and association with non-specific low back pain. Eur Spine J 2008;17:1407-22.

22. Dongfeng R, Hou S, Wu W, et al. The expression of tumor necrosis factor-alpha and CD68 in high-intensity zone of lumbar intervertebral disc on magnetic resonance image in the patients with low back pain. Spine (Phila Pa 1976) 2011;36:E429-33.

23. Zhou Y, Abdi S. Diagnosis and minimally invasive treatment of lumbar discogenic pain: a review of the literature. Clin J Pain 2006;22:468-81.

24. Gill K, Blumenthal SL. Functional results after anterior lumbar fusion at L5-S1 in patients with normal and abnormal MRI scans. Spine (Phila Pa 1976) 1992; 17:940-2.

25. Margetic P, Pavic R, Stancic MF. Provocative discography screening improves surgical outcome. Wien Klin Wochenschr 2013;125:600-10.

26. Moore KR, Pinto MR, Butler LM. Degenerative disc disease treated with combined anterior and posterior arthrodesis and posterior instrumentation. Spine (Phila Pa 1976) 2002;27:1680-6.

27. Colhoun E, McCall IW, Williams L, Cassar Pullicino VN. Provocation discography as a guide to planning operations on the spine. J Bone Joint Surg Br 1988;70: 267-71.

28. Manchikanti L, Boswell MV, Singh V, et al. Comprehensive evidence-based guidelines for interventional techniques in the management of chronic spinal pain. Pain Physician 2009;12:699-802.

29. Simmons JW, Emery SF, McMillin JN, Landa D, 
Kimmich SJ. Awake discography: a comparison study with magnetic resonance imaging. Spine (Phila $\mathrm{Pa}$ 1976) 1991;16(6 Suppl):S216-21.

30. Berg S, Isberg B, Josephson A, Fallman M. The impact of discography on the surgical decision in patients with chronic low back pain. Spine J 2012;12:283-91.

31. Carragee EJ, Don AS, Hurwitz EL, Cuellar JM, Carrino JA, Herzog R. 2009 ISSLS Prize Winner: Does discography cause accelerated progression of degeneration changes in the lumbar disc: a ten-year matched cohort study. Spine (Phila Pa 1976) 2009;34:2338-45.

32. Schellhas KP, Pollei SR, Gundry CR, Heithoff KB. Lumbar disc high-intensity zone. Correlation of magnetic resonance imaging and discography. Spine (Phila Pa 1976) 1996;21:79-86.

33. Braithwaite I, White J, Saifuddin A, Renton P, Taylor BA. Vertebral end-plate (Modic) changes on lumbar spine MRI: correlation with pain reproduction at lumbar discography. Eur Spine J 1998;7:363-8.

34. Weishaupt D, Zanetti M, Hodler J, et al. Painful lumbar disk derangement: relevance of endplate abnormalities at MR imaging. Radiology 2001;218:420-7.

35. Wolfer LR, Derby R, Lee JE, Lee SH. Systematic review of lumbar provocation discography in asymptomatic subjects with a meta-analysis of false-positive rates. Pain Physician 2008;11:513-38.

36. Hebelka H, Hansson T. HIZ's relation to axial load and low back pain: investigated with axial loaded MRI and pressure controlled discography. Eur Spine J 2013;22:734-9.

37. Ohtori S, Kinoshita T, Yamashita M, et al. Results of surgery for discogenic low back pain: a randomized study using discography versus discoblock for diagnosis. Spine (Phila Pa 1976) 2009;34:1345-8.

38. Bartynski WS, Rothfus WE. Peripheral disc margin shape and internal disc derangement: imaging correlation in significantly painful discs identified at provocation lumbar discography. Interv Neuroradiol 2012;18:227-41.

39. Ohtori S, Inoue G, Orita S, et al. No acceleration of intervertebral disc degeneration after a single injection of bupivacaine in young age group with followup of 5 years. Asian Spine J 2013;7:212-7.

40. Putzier M, Strube P. Answer to the Letter to the Editor of Jianqiang Ni et al. concerning "ALIF and total disc replacement versus 2-level circumferential fusion with TLIF: a prospective, randomized, clinical and radiological trial" by Hoff EK, Strube P, Pumberger M, et al. (2015) Eur Spine J. doi:10.1007/ s00586-015-3852-y. Eur Spine J 2015;24:2347-9.

41. Brox JI, Sorensen R, Friis A, et al. Randomized clinical trial of lumbar instrumented fusion and cognitive intervention and exercises in patients with chronic low back pain and disc degeneration. Spine (Phila Pa 1976) 2003;28:1913-21.

42. Fairbank J, Frost H, Wilson-MacDonald J, et al. Randomised controlled trial to compare surgical stabilisation of the lumbar spine with an intensive rehabilitation programme for patients with chronic low back pain: the MRC spine stabilisation trial. BMJ 2005;330:1233.

43. Celestre PC, Montgomery SR, Kupperman AI, Aghdasi B, Inoue H, Wang JC. Lumbar clinical adjacent segment pathology: predilection for proximal levels. Spine (Phila Pa 1976) 2014;39:172-6.

44. Kim HJ, Kang KT, Chun HJ, Lee CK, Chang BS, Yeom JS. The influence of intrinsic disc degeneration of the adjacent segments on its stress distribution after one-level lumbar fusion. Eur Spine J 2015;24:82737.

45. Ren C, Song Y, Liu L, Xue Y. Adjacent segment degeneration and disease after lumbar fusion compared with motion-preserving procedures: a meta-analysis. Eur J Orthop Surg Traumatol 2014;24 Suppl 1:S24553.

46. Horsting PP, Pavlov PW, Jacobs WC, Obradov-Rajic M, de Kleuver M. Good functional outcome and adjacent segment disc quality 10 years after single-level anterior lumbar interbody fusion with posterior fixation. Global Spine J 2012;2:21-6.

47. Bjarke Christensen F, Stender Hansen E, Laursen M, Thomsen K, Bunger CE. Long-term functional outcome of pedicle screw instrumentation as a support for posterolateral spinal fusion: randomized clinical study with a 5-year follow-up. Spine (Phila Pa 1976) 2002;27:1269-77.

48. Bono CM, Lee CK. Critical analysis of trends in fusion for degenerative disc disease over the past 20 years: influence of technique on fusion rate and clinical outcome. Spine (Phila Pa 1976) 2004;29:455-63.

49. Bono CM, Lee CK. The influence of subdiagnosis on radiographic and clinical outcomes after lumbar fusion for degenerative disc disorders: an analysis of the literature from two decades. Spine (Phila $\mathrm{Pa}$ 
1976) 2005;30:227-34.

50. Kim HJ, Kang KT, Son J, Lee CK, Chang BS, Yeom JS. The influence of facet joint orientation and tropism on the stress at the adjacent segment after lumbar fusion surgery: a biomechanical analysis. Spine J 2015; 15:1841-7.

51. Harrop JS, Youssef JA, Maltenfort M, et al. Lumbar adjacent segment degeneration and disease after arthrodesis and total disc arthroplasty. Spine (Phila Pa 1976) 2008;33:1701-7.

52. Park P, Garton HJ, Gala VC, Hoff JT, McGillicuddy JE. Adjacent segment disease after lumbar or lumbosacral fusion: review of the literature. Spine (Phila Pa 1976) 2004;29:1938-44.

53. Lorenz M, Zindrick M, Schwaegler P, et al. A comparison of single-level fusions with and without hardware. Spine (Phila Pa 1976) 1991;16(8 Suppl):S455-8.

54. Fritzell P, Hagg O, Wessberg P, Nordwall AA; Swedish Lumbar Spine Study Group. Chronic low back pain and fusion: a comparison of three surgical techniques: a prospective multicenter randomized study from the Swedish lumbar spine study group. Spine (Phila Pa 1976) 2002;27:1131-41.

55. Weatherley CR, Prickett CF, O’Brien JP. Discogenic pain persisting despite solid posterior fusion. J Bone Joint Surg Br 1986;68:142-3.

56. Shetty AP, Osti OL, Abraham G, Sebben R. Cylindrical threaded cages for lumbar degenerative disc disease: a prospective long term radiological study. Proceeding of the International Society for the Study of the Lumbar Spine; 2000 April; Adelaide, Australia.

57. Kim CW, Siemionow K, Anderson DG, Phillips FM. The current state of minimally invasive spine surgery. Instr Course Lect 2011;60:353-70.

58. Skovrlj B, Gilligan J, Cutler HS, Qureshi SA. Minimally invasive procedures on the lumbar spine. World J Clin Cases 2015;3:1-9.

59. Parker SL, Lerner J, McGirt MJ. Effect of minimally invasive technique on return to work and narcotic use following transforaminal lumbar inter-body fusion: a review. Prof Case Manag 2012;17:229-35.

60. Wiltse LL, Spencer CW. New uses and refinements of the paraspinal approach to the lumbar spine. Spine (Phila Pa 1976) 1988;13:696-706.

61. Shunwu F, Xing Z, Fengdong Z, Xiangqian F. Minimally invasive transforaminal lumbar interbody fusion for the treatment of degenerative lumbar dis- eases. Spine (Phila Pa 1976) 2010;35:1615-20.

62. Gragnaniello C, Seex KA. Anterior to psoas fusion of the lumbar spine. Neurosurg Focus 2013;35(2 Suppl):Video 13.

63. Cheng I, Briseno MR, Arrigo RT, Bains N, Ravi S, Tran A. Outcomes of two different techniques using the lateral approach for lumbar interbody arthrodesis. Global Spine J 2015;5:308-14.

64. Formica M, Berjano P, Cavagnaro L, Zanirato A, Piazzolla A, Formica C. Extreme lateral approach to the spine in degenerative and post traumatic lumbar diseases: selection process, results and complications. Eur Spine J 2014;23 Suppl 6:684-92.

65. Sofianos DA, Briseno MR, Abrams J, Patel AA. Complications of the lateral transpsoas approach for lumbar interbody arthrodesis: a case series and literature review. Clin Orthop Relat Res 2012;470:1621-32.

66. Mobbs RJ, Loganathan A, Yeung V, Rao PJ. Indications for anterior lumbar interbody fusion. Orthop Surg 2013;5:153-63.

67. Penta M, Sandhu A, Fraser RD. Magnetic resonance imaging assessment of disc degeneration 10 years after anterior lumbar interbody fusion. Spine (Phila Pa 1976) 1995;20:743-7.

68. Garg J, Woo K, Hirsch J, Bruffey JD, Dilley RB. Vascular complications of exposure for anterior lumbar interbody fusion. J Vasc Surg 2010;51:946-50.

69. Mobbs RJ, Phan K, Daly D, Rao PJ, Lennox A. Approach-related complications of anterior lumbar interbody fusion: results of a combined spine and vascular surgical team. Global Spine J 2016;6:147-54.

70. Sim EM, Claydon MH, Parker RM, Malham GM. Brief intraoperative heparinization and blood loss in anterior lumbar spine surgery. J Neurosurg Spine 2015;23:309-13.

71. Bateman DK, Millhouse PW, Shahi N, et al. Anterior lumbar spine surgery: a systematic review and metaanalysis of associated complications. Spine J 2015;15: 1118-32.

72. Flynn JC, Hoque MA. Anterior fusion of the lumbar spine. End-result study with long-term follow-up. J Bone Joint Surg Am 1979;61:1143-50.

73. Lee CS, Hwang CJ, Lee DH, Kim YT, Lee HS. Fusion rates of instrumented lumbar spinal arthrodesis according to surgical approach: a systematic review of randomized trials. Clin Orthop Surg 2011;3:39-47.

74. Gerber M, Crawford NR, Chamberlain RH, Fifield 
MS, LeHuec JC, Dickman CA. Biomechanical assessment of anterior lumbar interbody fusion with an anterior lumbosacral fixation screw-plate: comparison to stand-alone anterior lumbar interbody fusion and anterior lumbar interbody fusion with pedicle screws in an unstable human cadaver model. Spine (Phila Pa 1976) 2006;31:762-8.

75. Zhang Q, Yuan Z, Zhou M, Liu H, Xu Y, Ren Y. A comparison of posterior lumbar interbody fusion and transforaminal lumbar interbody fusion: a literature review and meta-analysis. BMC Musculoskelet Disord 2014;15:367.

76. Molinari RW, Saleh A, Molinari R Jr, Hermsmeyer J, Dettori JR. Unilateral versus bilateral instrumentation in spinal surgery: a systematic review. Global Spine J 2015;5:185-94.

77. Penta M, Fraser RD. Anterior lumbar interbody fusion: a minimum 10-year follow-up. Spine (Phila Pa 1976) 1997;22:2429-34.

78. Videbaek TS, Christensen FB, Soegaard R, et al. Circumferential fusion improves outcome in comparison with instrumented posterolateral fusion: longterm results of a randomized clinical trial. Spine (Phila Pa 1976) 2006;31:2875-80.

79. Soegaard R, Bunger CE, Christiansen T, Hoy K, Eiskjaer SP, Christensen FB. Circumferential fusion is dominant over posterolateral fusion in a long-term perspective: cost-utility evaluation of a randomized controlled trial in severe, chronic low back pain. Spine (Phila Pa 1976) 2007;32:2405-14.

80. Mobbs RJ, Sivabalan P, Li J. Minimally invasive surgery compared to open spinal fusion for the treatment of degenerative lumbar spine pathologies. J Clin Neurosci 2012;19:829-35.

81. Wardlaw D, Choudhary S, Muthukumar T, Gibson S. Allograft versus autograft in instrumented posterolateral lumbar spinal fusion: a randomized control trial. Orthop Proc 2005;87B(SUPP III):238-9.

82. Thalgott JS, Giuffre JM, Klezl Z, Timlin M. Anterior lumbar interbody fusion with titanium mesh cages, coralline hydroxyapatite, and demineralized bone matrix as part of a circumferential fusion. Spine J 2002;2:63-9.

83. Burkus JK, Gornet MF, Dickman CA, Zdeblick TA. Anterior lumbar interbody fusion using rhBMP-2 with tapered interbody cages. J Spinal Disord Tech 2002;15:337-49.
84. Burkus JK, Gornet MF, Schuler TC, Kleeman TJ, Zdeblick TA. Six-year outcomes of anterior lumbar interbody arthrodesis with use of interbody fusion cages and recombinant human bone morphogenetic protein-2. J Bone Joint Surg Am 2009;91:1181-9.

85. Smoljanovic T, Siric F, Bojanic I. Six-year outcomes of anterior lumbar interbody arthrodesis with use of interbody fusion cages and recombinant human bone morphogenetic protein-2. J Bone Joint Surg Am 2010;92:2614-5.

86. Scott-Young M. The incidence of retrograde ejaculation following anterior lumbar interbody fusion using RHBMP2 in 376 male patients. Proceedings of the Spine Society of Australia 25th Annual Scientific Meeting combined with the Scoliosis Research Society Worldwide Course; 2014 Apr 11; Brisbane, Queensland, Australia.

87. Malham GM, Parker RM, Ellis NJ, Blecher CM, Chow FY, Claydon MH. Anterior lumbar interbody fusion using recombinant human bone morphogenetic protein-2: a prospective study of complications. J Neurosurg Spine 2014;21:851-60.

88. Mobbs RJ, Chung M, Rao PJ. Bone graft substitutes for anterior lumbar interbody fusion. Orthop Surg 2013;5:77-85.

89. Fernstrom U. Arthroplasty with intercorporal endoprothesis in herniated disc and in painful disc. Acta Chir Scand Suppl 1966;357:154-9.

90. Guyer RD, McAfee PC, Banco RJ, et al. Prospective, randomized, multicenter Food and Drug Administration investigational device exemption study of lumbar total disc replacement with the CHARITE artificial disc versus lumbar fusion: five-year followup. Spine J 2009;9:374-86.

91. Murrey D, Janssen M, Delamarter R, et al. Results of the prospective, randomized, controlled multicenter Food and Drug Administration investigational device exemption study of the ProDisc-C total disc replacement versus anterior discectomy and fusion for the treatment of 1-level symptomatic cervical disc disease. Spine J 2009;9:275-86.

92. Gornet MF, Burkus JK, Dryer RF, Peloza JH. Lumbar disc arthroplasty with Maverick disc versus standalone interbody fusion: a prospective, randomized, controlled, multicenter investigational device exemption trial. Spine (Phila Pa 1976) 2011;36:E1600-11.

93. Lu SB, Hai Y, Kong C, et al. An 11-year minimum 
follow-up of the Charite III lumbar disc replacement for the treatment of symptomatic degenerative disc disease. Eur Spine J 2015;24:2056-64.

94. Siepe CJ, Mayer HM, Heinz-Leisenheimer M, Korge A. Total lumbar disc replacement: different results for different levels. Spine (Phila Pa 1976) 2007;32:782-90.

95. Rainey S, Blumenthal SL, Zigler JE, Guyer RD, Ohnmeiss DD. Analysis of adjacent segment reoperation after lumbar total disc replacement. Int J Spine Surg 2012;6:140-4.

96. Min JH, Jang JS, Lee SH. Comparison of anteriorand posterior-approach instrumented lumbar interbody fusion for spondylolisthesis. J Neurosurg Spine 2007;7:21-6.

97. Wai EK, Santos ER, Morcom RA, Fraser RD. Magnetic resonance imaging 20 years after anterior lumbar interbody fusion. Spine (Phila Pa 1976) 2006;31: 1952-6.

98. Berg S, Tullberg T, Branth B, Olerud C, Tropp H. Total disc replacement compared to lumbar fusion: a randomised controlled trial with 2-year follow-up. Eur Spine J 2009;18:1512-9.

99. Lemaire JP, Carrier H, Sariali el H, Skalli W, Lavaste $\mathrm{F}$. Clinical and radiological outcomes with the Charite artificial disc: a 10-year minimum followup. J Spinal Disord Tech 2005;18:353-9.

100. David T. Long-term results of one-level lumbar arthroplasty: minimum 10-year follow-up of the CHARITE artificial disc in 106 patients. Spine (Phila Pa 1976) 2007;32:661-6.

101. Ciarpaglini R, Otten P, Sutter P, Duy VQ, Gautier E, Maestretti G. Sacroiliac joint syndrome 10 years after lumbar arthroplasty: the importance of spinopelvic alignment. Eur Spine J 2014;23 Suppl 6:720-4.

102. Mostofi K. Total disc arthroplasty for treating lumbar degenerative disc disease. Asian Spine J 2015;9: 59-64.

103. Yajun W, Yue Z, Xiuxin H, Cui C. A meta-analysis of artificial total disc replacement versus fusion for lumbar degenerative disc disease. Eur Spine J 2010; 19:1250-61.

104. Burkus JK, Transfeldt EE, Kitchel SH, Watkins RG, Balderston RA. Clinical and radiographic outcomes of anterior lumbar interbody fusion using recombinant human bone morphogenetic protein-2. Spine (Phila Pa 1976) 2002;27:2396-408.
105. Sasso RC, Kitchel SH, Dawson EG. A prospective, randomized controlled clinical trial of anterior lumbar interbody fusion using a titanium cylindrical threaded fusion device. Spine (Phila Pa 1976) 2004; 29:113-22.

106. Green A, Gilbert P, Scott-Young M, Abbott A. Physiotherapeutic rehabilitation following lumbar total disc replacement: a retrospective study. Physiother Res Int 2015 Apr 17 [Epub]. http://dx.doi. org/10.1002/pri.1630.

107. Dreischarf M, Schmidt H, Putzier M, Zander T. Biomechanics of the L5-S1 motion segment after total disc replacement: influence of iatrogenic distraction, implant positioning and preoperative disc height on the range of motion and loading of facet joints. J Biomech 2015;48:3283-91.

108. Rundell SA, Day JS, Isaza J, Guillory S, Kurtz SM. Lumbar total disc replacement impingement sensitivity to disc height distraction, spinal sagittal orientation, implant position, and implant lordosis. Spine (Phila Pa 1976) 2012;37:E590-8.

109. Chung SK, Kim YE, Wang KC. Biomechanical effect of constraint in lumbar total disc replacement: a study with finite element analysis. Spine (Phila Pa 1976) 2009;34:1281-6.

110. Moumene M, Geisler FH. Comparison of biomechanical function at ideal and varied surgical placement for two lumbar artificial disc implant designs: Mobile-Core Versus Fixed-Core. Spine 2007;32: 1840-51.

111. Putzier M, Funk JF, Schneider SV, et al. Charite total disc replacement: clinical and radiographical results after an average follow-up of 17 years. Eur Spine J 2006;15:183-95.

112. Meir AR, Freeman BJ, Fraser RD, Fowler SM. Tenyear survival and clinical outcome of the AcroFlex lumbar disc replacement for the treatment of symptomatic disc degeneration. Spine J 2013;13:13-21.

113. Uschold TD, Fusco D, Germain R, Tumialan LM, Chang SW. Cervical and lumbar spinal arthroplasty: clinical review. AJNR Am J Neuroradiol 2012;33: 1631-41.

114. Gornet MF, Burkus JK, Harper ML, Chan FW, Skipor AK, Jacobs JJ. Prospective study on serum metal levels in patients with metal-on-metal lumbar disc arthroplasty. Eur Spine J 2013;22:741-6.

115. Auerbach JD, Jones KJ, Fras CI, Balderston JR, 
Rushton SA, Chin KR. The prevalence of indications and contraindications to cervical total disc replacement. Spine J 2008;8:711-6.

116. McAfee PC. The indications for lumbar and cervical disc replacement. Spine J 2004;4(6 Suppl):177S-181S.

117. Di Silvestre M, Bakaloudis G, Lolli F, Vommaro F, Parisini P. Two-level total lumbar disc replacement. Eur Spine J 2009;18 Suppl 1:64-70.

118. Trincat S, Edgard-Rosa G, Geneste G, Marnay T. Two-level lumbar total disc replacement: functional outcomes and segmental motion after 4 years. Orthop Traumatol Surg Res 2015;101:17-21.

119. Scott-Young M. Two level lumbar disc replacement: retrospective study of 79 patients with minimum follow-up period of one year. Spine J 2005;5(4 Suppl):S166.

120. Schatz C, Ritter-Lang K, Gossel L, Dressler N. Comparison of single-level and multiple-level outcomes of total disc arthroplasty: 24-month results. Int J Spine Surg 2015;9:14.

121. Yue J, Zhang K, Bai HX, et al. A comparison of patients who have undergone 1-Level versus 2-Level ProDisc arthroplasty: a prospective study with minimum of 5-year follow-up. Spine 2013;38:11948.

122. Galbusera F, Bellini CM, Zweig T, et al. Design concepts in lumbar total disc arthroplasty. Eur Spine J 2008;17:1635-50.

123. Pettine K, Ryu R, Techy F. Why Lumbar Artificial
Disc Replacements (LADRs) Fail. J Spinal Disord Tech 2016 Jul 14 [Epub]. http://dx.doi.org/10.1097/ BSD.0000000000000310.

124. Hoff EK, Strube P, Pumberger M, Zahn RK, Putzier M. ALIF and total disc replacement versus 2-level circumferential fusion with TLIF: a prospective, randomized, clinical and radiological trial. Eur Spine J 2016;25:1558-66.

125. Aunoble S, Meyrat R, Al Sawad Y, Tournier C, Leijssen P, Le Huec JC. Hybrid construct for two levels disc disease in lumbar spine. Eur Spine J 2010;19: 290-6.

126. Kasis A, Scott-Young A, Magno C, Nielsen D, Mitchell E, Blanch N. Combined Arthroplasty and Anterior Lumbar Interbody Fusion (Hybrid Procedure) in 385 patients with a minimum of 2 years follow-up. Proceedings of the International Society for the Advancement of Spine Surgery; 2012 Mar2123; Barcelona, Spain.

127. Mehrkens A, Muller AM, Valderrabano V, Scharen $S$, Vavken P. Tissue engineering approaches to degenerative disc disease: a meta-analysis of controlled animal trials. Osteoarthritis Cartilage 2012;20:131625.

128. Fukui S, Nitta K, Iwashita N, Tomie H, Nosaka S, Rohof O. Results of intradiscal pulsed radiofrequency for lumbar discogenic pain: comparison with intradiscal electrothermal therapy. Korean J Pain 2012;25:155-60. 